\title{
Dimensões transdisciplinares do trabalho de equipe em intervenção precoce
}

\author{
Vítor Franco \\ Universidade de Évora - Portugal
}

\begin{abstract}
RESUMO
O reconhecimento da importância dos primeiros tempos de vida no desenvolvimento da criança mudou significativamente os campos da educação, saúde e proteção social. A Intervenção Precoce representa a preocupação intencional de intervir ao nível do desenvolvimento, nomeadamente junto das crianças mais pequenas que se encontram em risco de ter o seu percurso afetado. Mais do que a solução para problemas específicos, falhas ou deficiências, o que está em causa é o desenvolvimento global, presente e futuro, da criança, bem como da família e do contexto que a rodeiam. Esta perspectiva global do desenvolvimento exige que o ponto de referência para os cuidados terapêuticos e educativos seja, sempre, a pessoa encarada como um todo. A multiplicidade de profissionais e de saberes não pode implicar o retalhamento da individualidade da criança ou a segmentação das suas necessidades. A abordagem transdisciplinar permite ultrapassar as limitações de cada formação disciplinar específica e ir ao encontro desta criança complexa, mas una, e do seu contexto. Pretendemos refletir sobre as principais características e potencialidades do trabalho transdisciplinar no âmbito da Intervenção Precoce, mostrando exemplos de como a sua utilização pode ser concretizada nos domínios da deteç̧ão, avaliação, intervenção e acompanhamento das crianças.
\end{abstract}

Palavras-chave: intervenção precoce; transdisciplinaridade; equipe de intervenção.

\section{ABSTRACT \\ Transdisciplinary dimensions of team work in early intervention}

The recognition of the importance of the early life in the development of children has lead to significant changes in care, education and health systems. Early intervention represents an intentional concern to interfere in the development of the children, especially those who, showing a real or potential disturbance, are in great danger of having their development affected. However, instead of finding solutions to specific problems or handicaps, the aim here is to see the child present and future development as a whole, as well as its family and background. This global approach demands that both therapeutical and educative cares always view the Person as a whole. The multiplicity of professionals and acquirements cannot lead to the fragmentation of the child individuality o its needs. On the other hand, a transdisciplinary perspective allows passing beyond the limitations of each specific subject training in order to meet this complex, yet one only child and its context. We intend to think about the features and potentialities of transdisciplinary work in early intervention, introducing examples on how it can be used on detection, evaluation, intervention and care of these children.

Keywords: early intervention; transdisciplinarity; intervention team.

\section{DIMENSÕES TRANSDISCIPLINARES DOS SABERES TEÓRICOS E PRÁTICOS}

São os quadros de referência teóricos e técnicos que habitualmente utilizamos que nos conduzem nas nossas abordagens da realidade. Olhando para uma mesma realidade, as formas que dela emergem estão de acordo com o que nos habilita a vê-las: a nossa experiência, expectativas, valores, formação e personalidade.
O próprio progresso da ciência e dos saberes práticos assenta nesta possibilidade de segmentar o real de forma a melhor podermos lidar com ele, ou seja, de o conhecermos mais profunda e minuciosamente e sobre ele produzirmos conhecimento.

O nascimento da ciência moderna e contemporânea trouxe como conseqüência um deslocamento do estatuto da verdade do sujeito para o objeto... Nós nos dirigimos, na busca da verdade, muito mais ao objeto que ao sujeito... esta suposição de que a verdade opera assim, ou seja, que está absolutamente 
colada ao objeto... permeia a Psicologia e, portanto, permeia as diversas disciplinas que se alimentam dela. E uma vez que se supõe que a verdade está no objeto, quanto menor o objeto, maior o nível de certeza que sobre ele se pode atingir. Assim é que surge a fragmentação que vai dar nas especializações... É por isso que o discurso das especialidades faz a resistência à interrogação sobre a subjetividade. (Kupfer, 2000, p. 86)

Ao nível da formação e das práticas profissionais, isto tem conduzido a uma maior especialização, em que cada profissional sabe cada vez mais do seu domínio (que se vai estreitando) sabendo cada vez menos dos restantes. Nessa medida, o distanciamento em relação ao real total tenderá a aumentar por parte da generalidade dos profissionais.

Também no que se refere ao desenvolvimento das crianças com deficiência ou com algum tipo de perturbação, este mesmo movimento levou a que tivessem sido entregues a especialistas. Primeiro aos especialistas em educação, peritos em perturbações do desenvolvimento, ou educação especial, entregando o problema para ser resolvido por quem melhor se esperava que o pudesse entender, numa perspectiva unifatorial.

A primeira conseqüência deste movimento foi que à idéia de Pessoa se sobrepôs a de deficiente, ou de patologia, problema e limitação. O objetivo passou a ser a reabilitação, e esta seria a finalidade de toda a intervenção, ou conjunto das diferentes intervenções. Tratava-se de resolver, minorar ou atenuar as conseqüências e implicações do problema num domínio especifico. Os serviços passaram a organizar-se tendo em conta a especificidade da patologia, ou deficiência, e os técnicos passaram a ser chamados em função do contributo específico trazido para a compreensão ou intervenção naquela patologia.

Num segundo momento, foi a própria concepção de deficiência que se pulverizou face à diversificação e especialização dos saberes. Perdida a importância da noção de Pessoa, facilmente o, até aí, "deficiente" passou a ser atendido por múltiplos especialistas, cada um na área da sua especialidade e de acordo com as patologias ou as necessidades específicas. Os cuidados que passaram a ser prestados foram os derivados ou requeridos por essa patologia, sendo que tudo o mais deixou de ser considerado por se situar fora do âmbito desse especialista.

A segmentação disciplinar dos saberes relaciona-se diretamente com uma forma de abordar, pensar e intervir sobre a realidade. Em que a Pessoa, no seu todo, é subalternizada pela lógica da segmentação em função dos saberes, práticas e técnicas.

Apesar de tudo, a expressão "Pessoa portadora de deficiência” remeteu para uma abordagem em que a pessoa readquire o primeiro lugar. Esta pequena mudança é relevante a dois níveis. Primeiramente, situa as necessidades e problemáticas no campo dos direitos da pessoa, dos direitos humanos, dando uma nova dimensão às questões da inclusão, mas também, de um modo mais específico, a todas as práticas e serviços prestados a essas pessoas. A um segundo nível, aquele que agora mais nos interessa, remete-nos para a necessidade de retomar uma perspectiva holística, integrada e multidimensional de pessoa. A questão é: quem trata da Pessoa? Sabemos quem cuida dos aspectos motores, dos problemas com os dentes ou o estômago, das aprendizagens ou até das carências sociais específicas. Mas se a Pessoa é mais do que isso, quem é, ou quem são, os técnicos capazes de abordar e responder às suas necessidades? Nem precisamos colocar a nossa interrogação numa perspectiva existencial, podemos começar mesmo por nos interrogar no domínio pragmático dos cuidados.

A Pessoa é o sujeito e o objeto dos cuidados. E o valor de uma intervenção específica (seja educativa ou médico-cirúrgica) tem de ser sempre avaliada tendo em conta este princípio. Por isso temos de reencontrar hoje alguns movimentos de busca da totalidade e da síntese complexa de cada indivíduo.

Se pensarmos ainda que a Pessoa é ela e mais os seus contextos e as suas relações, qual poderá ser o profissional capaz de cuidar de toda essa complexidade? Esta exigirá um novo profissional ou mais uma nova profissionalidade? Certamente uma nova prática profissional que não perca de vista o todo e o multidimensional. A necessidade de trabalhar com o outro, de se ultrapassar o domínio disciplinar, é, assim, um imperativo para um trabalho deste tipo que aponta para a inclusão educativa plena (Correia, 1997; Simon, 1991; Unesco, 1994).

Cuidar das crianças no seu todo exige também uma perspectiva de desenvolvimento, e a humildade de reconhecermos a nossa inevitável incompetência para resolver o problema, ou a parte mais importante do problema. Para assim podermos aceitar que tudo aquilo que encontremos no quadro do nosso pensamento profissional é apenas uma parte desse problema ou da sua solução, limitada sempre pelo papel que a família e os outros técnicos possam ter nela. Quando 
hoje pensamos sobre a necessidade de cuidarmos do desenvolvimento das crianças desde muito cedo, especialmente daquelas que por alguma razão o têm ameaçado, temos de o fazer a partir desta perspectiva, sem a ilusão de soluções simples e milagrosas.

A Intervenção Precoce, como cuidado do desenvolvimento infantil, vai ao encontro da necessidade de perspectivas de Pessoa e de Desenvolvimento que ultrapassem as limitações disciplinares. A transdisciplinaridade oferece-se à Intervenção Precoce como uma abordagem promissora e profícua, que pode ultrapassar as limitações de uma prática educativa meramente disciplinar, e também oferecer uma metodologia de trabalho mais abrangente e integradora. É nossa intenção refletir sobre as principais características e potencialidades do trabalho transdisciplinar no âmbito da Intervenção Precoce, mostrando como a sua utilização pode ser concretizada nos domínios da detecção, avaliação, intervenção e acompanhamento das crianças até aos seis anos.

\section{A TRANSDISCIPLINARIDADE NA INTERVENÇÃO PRECOCE}

\section{A Intervenção Precoce}

A Intervenção Precoce tem deixado de ser um serviço de estimulação pontual das crianças com deficiência, transtornos do desenvolvimento ou objeto de algum tipo de maltrato social (Bailey, Hebbeler, Scarborough, Spiker \& Malik, 2004). O conceito de Estimulação Precoce, que a precedeu, centrava-se especificamente sobre a necessidade de estimular a criança, pondo em ação as suas competências motoras e sensoriais, de forma a obter maior qualidade nesses domínios. Hoje, o conceito de Intervenção Precoce é mais vasto e dimensional, podendo ser definido como o conjunto das intervenções dirigidas às crianças, até aos 6 anos, com problemas de desenvolvimento ou em risco de os virem a apresentar, suas famílias (Correia \& Serrano, 1998) e contextos, tendo por objetivo responder, o mais cedo possível, às necessidades, transitórias ou permanentes que apresentam. Torna-se assim parte essencial dos sistemas educativos, de saúde e de proteção social à infância nos diferentes países.

São crianças com perturbações do desenvolvimento todas as que apresentam qualquer alteração no curso normal de desenvolvimento, e em situação de risco aquelas em que se detecta a probabilidade de ocorrer uma alteração desse tipo. Entre os fatores de risco incluem-se as situações de privação ambien- tal, que podem limitar a capacidade da criança tirar o máximo de partido de experiências de aprendizagem fundamentais, fatores de risco biológico (por exemplo, as resultantes de um quadro de prematuridade) e fatores de risco decorrentes de condições médicas específicas ou síndromes (Apolónio, Rubin, Castilho \& Franco, 2000).

A Intervenção Precoce assenta sobre os contributos conceptuais que lhe são fornecidos por três grandes áreas do saber: as neurociências, a investigação sobre desenvolvimento dos bebês e as perspectivas contextuais e ecológicas do desenvolvimento. Das Neurociências recebeu a ênfase na fragilidade e maleabilidade neurológica dos bebês e das crianças pequenas, o que por um lado as torna mais vulneráveis às situações de risco, mas, por outro, faz com que também tenham uma maior plasticidade, permitindo que uma intervenção que ocorra mais precocemente possa ter maior impacto e maior probabilidade de alcançar bons resultados.

A investigação na área do desenvolvimento infantil, por seu lado, permitiu atribuir uma importância fundamental à relação interpessoal mãe-bebê, mostrando que a boa qualidade das relações desempenha um papel fulcral no desenvolvimento das crianças, assim como também conhecer melhor o papel ativo do bebê e as competências do recém-nascido, salientando o seu potencial para agir socialmente. Isto contribuiu para se passar a dar mais atenção e valor às interações precoces no processo de desenvolvimento, levando a que, de uma intervenção centrada exclusivamente na criança, se evoluísse para uma intervenção mais preocupada com a qualidade e natureza das interações.

Por outro lado, as perspectivas contextuais e ecológicas do desenvolvimento evidenciaram que este não se encontra apenas relacionado com os processos internos ou as interações, mas também com as relações com os diferentes contextos que circundam a criança, desde um nível de maior proximidade a um nível mais abrangente e lato.

A Intervenção Precoce pode ser definida também como

uma medida de apoio integrado centrada na criança e na família, mediante ações de natureza preventiva e habilitativa, designadamente do âmbito da educação, saúde e ação social, que permite assegurar condições facilitadoras do desenvolvimento da criança com deficiência ou em risco de atraso grave de desenvolvimento, potenciar as interações familiares como suporte da sua progressiva capacitação e auto- 
nomia face à problemática da deficiência. (Diário da República, 1999, p. 15.566)

Esta definição enuncia-nos os três grandes princípios da Intervenção Precoce: o princípio da globalidade, na medida em que encara a criança como um todo e o apoio como integrado. Defende que as ações a desenvolver nos diferentes domínios devem ser conjugadas e integradas. O princípio da contextualidade, porque a criança é vista no quadro do seu contexto de vida, não apenas familiar, mas também social e cultural. É, por isso, importante que na intervenção se conjuguem esforços de diferentes áreas e saberes, considerando-se não só os processos intrapessoais, mas também os interpessoais e as transações no âmbito do contexto social mais alargado. Por fim, o princípio da oportunidade, porque a intervenção deve ocorrer no tempo certo. Quer esse tempo certo seja antes do problema (perspectiva de prevenção) quer seja logo que possível (problema da detecção precoce), mas sempre de imediato.

Os grandes objetivos da Intervenção Precoce são assim: criar as condições mais facilitadoras do bom desenvolvimento e que permitam eliminar ou diminuir o risco; facilitar a integração da criança no meio familiar, escolar e social e a sua autonomia pessoal, através de uma redução dos efeitos de uma deficiência ou déficit; reforçar as boas relações e competências familiares através da promoção de uma boa base emocional de suporte; e introduzir mecanismos de compensação e de eliminação de barreiras. Tudo isto considerando sempre a criança como sujeito ativo no processo, envolvendo a comunidade na integração e fomentando redes de suporte emocional à criança e à família.

A Intervenção Precoce é um processo que se compõe de diferentes fases. A fase de detecção consiste no procurar, em toda a população, de forma sistemática, os indicadores para futuras medidas individualizadas. De seguida temos as fases de identificação ou sinalização, em que se procuram os sinais ou sintomas que sugerem que o desenvolvimento da criança pode estar em risco ou a progredir de forma atípica. Esta é uma dimensão preventiva fundamental porque para se intervir precocemente há que identificar e orientar precocemente. As fases de avaliação, diagnóstico e planejamento da intervenção, visam caracterizar a natureza da problemática em causa, as necessidades que daí decorrem, e planejar o bom uso dos recursos disponíveis. Por fim, a intervenção inclui todas as atividades dirigidas à criança, à sua família e ao ambiente, com o objetivo de criar condições favoráveis ao seu desenvolvimento.

Estas intervenções devem considerar sempre a globalidade da criança, sendo planificadas e implementadas por uma equipe de diferentes profissionais, numa orientação interdisciplinar ou transdisciplinar (Shonkoff \& Meisels, 2000).

\section{TRABALHO DE EQUIPE EM INTERVENÇÃO PRECOCE}

Todas estas fases são levadas a cabo por equipes formadas por diferentes profissionais, com formação especializada nos respectivos domínios, que lhes dá a qualificação adequada para exercer eficazmente as suas funções. Cada equipe de Intervenção Precoce é "uma unidade funcional composta por indivíduos com formação especializada e variada e que coordenam as suas atividades a fim de prestar os seus serviços às crianças e famílias” (Golin \& Ducanis, 1981, p. 24).

Se é certo que a Intervenção Precoce exige uma multiplicidade de saberes, formações e intervenções que têm de se fazer conjugadamente, podemos considerar que existem três grandes modelos de organização e trabalho em equipe: multidisciplinar, interdisciplinar e transdisciplinar. A forma como estas equipes se organizam pode diferir bastante. Os profissionais, oriundos das diferentes áreas do saber, tanto podem atuar conjuntamente como de uma forma individualizada com uma mesma criança, numa mesma problemática, consoante o modelo de intervenção que a equipe adotou na sua prática.

O modelo multidisciplinar reconhece a necessidade de múltiplos profissionais que avaliem e intervenham, de acordo com a situação e necessidades da criança, nomeadamente a sua patologia. No entanto, o resultado é mais o somatório das atividades individuais dos diferentes técnicos, que tendem a trabalhar e a tomar decisões isoladamente, não sendo postas em questão as suas perspectivas pessoais, porquanto se parte do princípio que cada um sabe o que é melhor para aquela situação. A orientação que cada técnico vai seguir depende da sua perspectiva profissional e da formação que possui e cada um tenderá a tomar decisões e a trabalhar isoladamente, sendo fraca a interligação e a coordenação entre as ações e os programas de intervenção. Este modelo pode conduzir a intervenções ou orientação dos casos eventualmente contraditórias ou concorrentes, sendo difícil a definição de prioridades. Assim como faz com que seja difícil 
chegar a entender a pessoa na sua globalidade e totalidade.

O modelo interdisciplinar é mais integrado que o anterior. Nele passa a existir uma estrutura formal de interação e de trabalho de equipe. A partilha de informação é mais freqüente e assumida como fundamental. No entanto, o fator decisivo nas tomadas de decisão sobre o planejamento ou a intervenção continua a ser a perspectiva de cada disciplina ou de cada especialista. Como é cada profissional que faz a sua própria avaliação e seleção de prioridades, a tomada de decisão quanto à orientação do caso tende a refletir as relações de poder entre os técnicos, mais do que as reais necessidades da criança ou da família.

O modelo que mais poderá adequar-se ao trabalho em Intervenção Precoce é o transdisciplinar. Em primeiro lugar supõe a existência de um conceito de equipe mais forte, estruturado e dinâmico em que:

a) há total co-responsabilidade, de todos os membros da equipe, nas tomadas de decisão e na avaliação dos resultados;

b) o dinamismo de toda a equipe, incluindo as interações de suporte mútuo entre os seus membros, é vivido como elemento fundamental do próprio trabalho e da respectiva qualidade;

c) é fundamental o suporte mútuo e a partilha de informação e conhecimento; e

d) cada técnico integra conhecimentos e estratégias que ultrapassam a sua formação de base.

Além disso, centra-se, fundamentalmente, nas necessidades da Pessoa e não na especialização dos técnicos. Em termos conceptuais, corresponde a um movimento mundial no sentido da integração dos saberes e da produção de novos tipos de conhecimento (CRET, 1994) e tem a sua concretização prática na forma de estruturar o trabalho em equipa (Iribarry, 2003).

\section{Dimensões práticas do modelo transdisciplinar}

O modelo transdisciplinar vai diferir bastante dos diferentes modelos de equipes multidisciplinares e interdisciplinares na abordagem das várias dimensões do trabalho em Intervenção Precoce (Ferreira, 2001). Vejamos como se organizam essas diferenças:

a) Detecção e sinalização dos casos para intervenção - Relativamente à detecção e identificação de casos elegíveis, o modelo transdisciplinar assenta no princípio da cooperação e articulação entre técnicos e serviços. Qualquer que seja o profissional que detecta a criança, encaminha-a o para a equipe de intervenção, em vez de elaborar logo o seu próprio programa de intervenção setorial ou de remeter a criança para múltiplas avaliações.

b) Avaliação da criança - No modelo transdisciplinar a avaliação é feita por todos os membros da equipe de forma compreensiva e global, em conjunto com a família que participa ativamente em todas as fases. Procura não duplicar processos de avaliação e que cada observação efetuada recolha o máximo de informação sobre o desenvolvimento global e cada uma das áreas de competência da criança. Enquanto que nas equipes multidisciplinares ou interdisciplinares a avaliação é feita em separado, por cada especialista, podendo existir mais ou menos partilha de informação, neste modelo procuram-se formas de avaliação que perturbem minimamente a atividade da criança, as suas relações.

c) Participação das famílias - A família participa ativamente em todo o processo, desde a avaliação até ao planejamento, implementação das ações e programas. Esta participação é um elemento fundamental, podendo considerar-se que a própria intervenção é centrada na família. Nos outros modelos a família, mesmo reunindo individualmente com cada técnico, ou com o representante da equipe, continua a ser sempre um elemento completamente exterior às tomadas de decisão técnicas.

d) Responsabilidade pela intervenção - Na perspectiva de funcionamento transdisciplinar, todos os elementos da equipe são co-responsáveis por todos os momentos da intervenção. É sempre a equipe que assume, coletivamente, a responsabilidade pela intervenção, independentemente das tarefas concretas atribuídas aos seus membros, contrariamente ao que acontece nas outras perspectivas, em que a responsabilidade é do técnico que faz a intervenção direta.

e) Planejamento da intervenção - Este é um dos domínios em que mais facilmente podemos verificar a mudança que uma perspectiva transdisciplinar traz para uma equipe de Intervenção Precoce. Enquanto que, nas outras perspectivas, cada técnico apenas participa no planejamento da intervenção no seu domínio específico de ação e, quando muito, na sua conjugação com outros interventores, aqui a equipe é responsável pela definição de um plano integrado, em que a família é igualmente chamada a participar, que tem em conta a globalidade das necessidades e dos recursos, e em que as prioridades são definidas em função da própria criança e família. 
f) Implementação do programa de intervenção No modelo transdisciplinar todos os técnicos são coresponsáveis pela implementação do programa, independentemente de quem o executa. Todos os técnicos têm permanentemente em consideração os objetivos definidos para a intervenção, havendo um responsável pela sua execução, o responsável de caso. Se um técnico desconhece o trabalho que a equipe está a desenvolver ou a forma como os pais estão envolvidos na intervenção (Correia \& Franco, 2005) certamente não estamos perante uma prática transdisciplinar.

g) Pressupostos de funcionamento da equipe - Todos os técnicos estão comprometidos em ensinar, aprender e trabalhar em conjunto para implementar planos de intervenção que ultrapassam os limites da sua disciplina. O que é bem mais do que o mero reconhecimento ou atribuição de espaço e valor às outras disciplinas. É assumir que as crianças e as famílias necessitam de uma boa equipe mais do que de um bom técnico.

h) Comunicação entre técnicos - As equipes transdisciplinares apostam na comunicação e partilha dos diversos saberes, integrando os conhecimentos e estratégias dos diferentes profissionais através de reuniões estruturadas e de uma ligação permanente. Noutros tipos de equipe, a comunicação entre membros tende a ser mais esporádica, em reuniões periódicas, encontros formais e consultas ou faz-se fundamentalmente através de registros e relatórios escritos.

i) Aprendizagem e formação dos técnicos - A formação dos técnicos assenta numa aprendizagem transdisciplinar, centrada nas problemáticas e não na formação de base. Cada um aprende com (ou a partir de) os outros elementos da equipe.

j) Implicações organizacionais - A prática transdisciplinar aponta para uma organização em equipes maleáveis, com partilha de responsabilidades, sendo o responsável de caso quem articula a equipe com a família. Fugindo assim à estrutura orgânica mais corporativa, por departamentos criados em função das especialidades (psicólogos, fisioterapeutas etc.).

\section{Exemplos de dimensões transdisciplinares}

As mudanças que a transdisciplinaridade exige e oferece na forma de trabalhar repercutem-se em múltiplos aspectos, muito particularmente no trabalho técnico e das equipes. É impossível pretender uma prática transdisciplinar querendo manter intacta a organização até aí multidisciplinar.
Temos encontrado muitas equipes fazendo a apologia do funcionamento transdisciplinar que nas suas práticas não conseguem fazer as alterações necessárias para ultrapassar as disciplinares (Correia \& Franco, 2005). Se nem os membros de uma mesma equipe possuem informação convergente sobre a criança, a família ou o trabalho que está a ser desenvolvido, isso é certamente um indicador claro de reduzido trabalho em equipe. Para podermos pensar mais profundamente sobre as implicações do trabalho transdisciplinar, apresentamos dois exemplos de como um modelo deste tipo exige mudanças mais ou menos radicais.

\section{Espaço da equipe}

Habitualmente os próprios espaços físicos são definidos em função das especificidades profissionais e das relações de poder entre profissionais ou suas hierarquias. Essas relações marcam-se, muitas vezes, pelo próprio espaço físico de que cada um dispõe (gabinete, sala de trabalho etc.).

Os serviços de atendimento de crianças também tendem a organizar-se assim: a sala do psicólogo, a sala o técnico de serviço social, a sala da educadora. A perspectiva subjacente é disciplinar, ou seja, a criança deve deslocar-se ao espaço próprio de um profissional que ali a acolhe, na sua privacidade. A criança é sempre uma visita, um intruso num espaço que tende a ser bem marcado e demarcado (pelas fotos, imagens, objetos pessoais, casacos, malas etc.) do profissional.

Por outro lado, o contacto entre profissionais exige que cada um deixe o seu espaço próprio e vá ao encontro do outro num espaço neutro (sala de reuniões) ou no de alguém hierarquicamente superior (e por isso com um gabinete maior). Tal organização e distribuição do espaço é dificilmente conciliável com uma perspectiva de trabalho de equipe e, mais ainda, com uma perspectiva transdisciplinar.

Tivemos oportunidade de implementar um outro conceito de definição e distribuição dos espaços no Centro de Desenvolvimento e Intervenção Precoce da Associação de Paralisia Cerebral de Évora, instituição que trabalha com crianças com paralisia cerebral e doenças neurológicas afins, possuindo uma equipa multidisciplinar. Foi decidido que não haveria gabinetes definidos e atribuídos em função dos técnicos, mas sempre em função das tarefas e dos serviços.

Daqui decorreram diretamente duas conseqüências:

$1^{\text {a }}$ - Os espaços passaram a ser definidos para as crianças. É cada criança, e cada binômio criança/atividade, que se apropria do espaço próprio. A sala de 
educação, o ginásio, a sala de atividade motora etc., pertencem à criança e é onde cada técnico vai trabalhar, ou não, consoante aquilo que está definido pelo seu próprio plano de intervenção. Os espaços tornamse mais polivalentes e, sendo partilhados pelos técnicos, são mais marcados e assumidos pelas crianças do que por estes.

$2^{\mathrm{a}}$ - Passou a existir uma sala de equipe, sala de trabalho de todos os técnicos quando não estão no atendimento direto das crianças. Esse espaço é não apenas o de reunião formal da equipe, como de encontro informal e permanente entre técnicos. Funcionando como espaço permanente interlocução e de suporte, os técnicos deixaram de trabalhar no isolamento dos seus gabinetes para passarem a dispor de um contexto verdadeiramente promotor do trabalho de equipe, promovendo também a proximidade afetiva, imprescindível ao trabalho com crianças com perturbações graves do desenvolvimento.

\section{Responsável de caso}

Um segundo exemplo refere-se à figura do responsável de caso, alguém que pode ter também uma função transdisciplinar.

A competência de gestão de um caso, ou seja, da situação de uma criança/família implicada num processo de Intervenção Precoce, é específica e ultrapassa os limites de qualquer formação especializada. Muitas vezes os técnicos se questionam como é possível explicar às famílias o que está a acontecer nesta ou naquela terapia e se tal explicação não terá de ser sempre dada pelo técnico que a está realizando. Independentemente desse técnico ser ou não chamado a estar com a família, com maior ou menor regularidade, numa equipe transdisciplinar o responsável de caso tem de estar em condições de se tornar interlocutor e suporte de cada família. Este não é trabalho apenas do psicólogo, ou do técnico de serviço social. Talvez, pela sua formação, estes possam estar mais preparados para desempenhar tal tarefa, tão intrinsecamente relacional, mas esse é o desafio formativo da transdisciplinaridade: o desenvolvimento de competências múltiplas que ultrapassem definitivamente o treino técnico que corresponde a uma especialidade. A formação transdisciplinar exige certamente o desenvolvimento de competências no domínio das relações interpessoais e do trabalho de equipe.

Por vezes afirma-se que a própria família deve ser considerada como parte integrante da equipe transdisciplinar. Talvez o seja na medida em que o seu envol- vimento é fundamental em toda a Intervenção Precoce e no sentido em que a informação e o conhecimento que traz são relevantes para a intervenção, participa ativamente nas diferentes fases do processo, as suas necessidades (explicitas ou não) são tidas em consideração e aprende com os técnicos quando eles partilham informação e a tornam assim mais capaz. Mas, por outro lado a família é também o usuário de um serviço e, por isso, tem direitos que se ligam com a qualidade do apoio que recebe. Não pode pois, ser responsabilizada e culpabilizada pelo que possa não correr bem no processo. Tem também direito a ser cuidada no seu próprio desenvolvimento (Franco \& Apolónio, 2002) e tem de ser respeitada e entendida nas suas limitações, fragilidades e necessidades. E isso é responsabilidade dos profissionais, ou seja, da equipe.

\section{CONCLUSÃO}

A crescente importância dada aos primeiros tempos de vida tem levado ao questionamento dos cuidados com o desenvolvimento das crianças menores e à procura da máxima eficácia na resposta às suas necessidades. A Intervenção Precoce surge, neste contexto, como uma procura intencional de intervir no desenvolvimento das crianças, especialmente aquelas que, pela perturbação existente, suspeitada ou apenas potencial, se encontram, de algum modo, em risco de ter o seu desenvolvimento afetado.

No entanto, não se trata de uma tentativa de remediar problemas específicos ou recuperar falhas objetivas e delimitadas, como o conceito, mais antigo, de Estimulação Precoce poderia sugerir. O que está em causa é todo o desenvolvimento da criança, a família e o contexto em que ele decorre.

Esta perspectiva global do desenvolvimento exige, assim, que os cuidados, terapêuticos, educativos ou outros, tenham de ter sempre como referência uma totalidade: a criança na sua complexidade e na multidimensionalidade das suas características e qualidades. A multiplicidade de profissionais e saberes não pode conduzir ao retalhamento da individualidade da criança, ou à segmentação das suas necessidades.

A abordagem transdisciplinar é mais do que uma forma de organização de equipe. Permite cuidar da criança (e família) como uma globalidade, indo ao encontro desta criança complexa, com o seu contexto. Pretende e permite cuidar da criança no seu todo, criança-familia-contexto porquanto desenvolve uma atitude face aos determinantes da intervenção que assume 
uma perspectiva global, sistêmica, contextual ou ecológica da Pessoa.

Ao nível da organização da equipe, a perspectiva transdisciplinar é também multidisciplinar porquanto subentende que a equipe é composta por profissionais de múltiplas formações e proveniências e, de certo modo, é também sempre interdisciplinar no sentido da interação e comunicação que tem de existir entre os seus membros. No entanto, além disso, pressupõe uma atitude quanto ao funcionamento da equipe, alicerçada na valorização da equipe enquanto instrumento prestador dos cuidados e em sentimentos de pertença e empenhamento. Tem em conta também a possibilidade de cada um encontrar o seu lugar no seio da equipe, com os confrontos necessários e a contestação que pode ser frutuosa. Outra das marcas fundamentais da transdisciplinaridade, a este nível do funcionamento de equipe, é a da co-responsabilidade.

Permite também ultrapassar as limitações da formação disciplinar, para melhor saber responder às necessidades reais da criança. Ultrapassa os limites do saber disciplinar na medida em que exige que os técnicos tenham uma atitude de partilha face aos seus próprios saberes, de disponibilidade para dar e receber informação, o que coloca exigências ao nível da utilização de uma linguagem, terminologia e conceitos que possam ser partilhados por toda a equipe e pelas próprias famílias. Isso passa também pela atitude face à comunicação e à transferência de conhecimentos e competências. Essa é sem dúvida a atitude fundamental do funcionamento transdisciplinar: exige um posicionamento de aceitação, receptividade e valorização perante o saber do outro.

As dificuldades em desenvolver uma prática transdisciplinar em Intervenção Precoce situam-se geralmente a dois níveis: o da formação transdisciplinar e da atitude face ao outro.

A prática transdisciplinar exige que, para além das competências técnicas específicas, os diferentes profissionais estejam preparados para o trabalho de equipe, nomeadamente para a cooperação. Exige ainda competências relacionadas com a comunicação e a partilha de informação e com o domínio da terminologia e conceitos que permitam o trabalho transdisciplinar. Cada profissional deve ser capaz de se situar perante cada caso ou problema (ou seja, situar a sua perspectiva de abordagem específica), mas sem deixar de situar o seu lugar no processo, sabendo identificar o seu contributo específico para todos os processos de tomada de decisão da equipe. Ainda ao nível da formação, a transdisciplinaridade exige uma postura de formação permanente a partir da própria equipe (e dos seus dife- rentes saberes) e do exterior, funcionando cada técnico como via de alimentação formativa de toda a equipe.

A atitude face ao outro passa, em primeiro lugar, pela possibilidade de aceitar e valorizar as suas competências, ultrapassando as tentações corporativas. Passa, depois, pela ênfase nas relações humanas, interpessoais, dentro do próprio grupo. É a qualidade dessa relação que vai ser decisiva no desenvolvimento da qualidade e competência da equipe, sendo também o suporte emocional do trabalho, emocionalmente duro, que se desenvolve na Intervenção Precoce. Passa ainda pelo encontrar estruturas organizacionais em que o conceito de equipe transdisciplinar não se choque com estruturas hierárquicas rígidas, em que os processos de decisão possam ser demasiado afetados por fatores exteriores ao funcionamento técnico da equipe.

\section{REFERÊNCIAS}

Apolónio, A., Rubin, L., Castilho, C., \& Franco, V. (2000). Intervenção precoce no desenvolvimento de crianças com paralisia cerebral. Em C. Machado e cols. (Org.), Interfaces da psicologia: Vol. I (p. 138-145). Évora: Universidade de Évora.

Bailey, D. B., Hebbeler, K., Scarborough, A., Spiker, D., \& Malik, S. (2004) First experiences with early intervention: a national perspective. Pediatrics, 113(4), 887-896

Correia, E., \& Franco, V. (2005). Envolvimento parental no trabalho terapêutico - Representações dos técnicos das equipes de Intervenção Precoce. Em F. Vicente Castro e cols. (Org.), Psicologia y educación: Nuevas investigaciones (p. 167-184). Infad: Universidad de Extremadura.

Correia, L. M. (1997). Alunos com necessidades educativas especiais nas classes regulares. Porto: Porto Editora .

Correia, L. M., \& Serrano, A. M. (1998). Envolvimento parental em intervenção precoce - das práticas centradas na criança à práticas centradas na família. Porto: Porto Editora.

CRET - Centre de Recherche et Études Transdisciplinarité (1994). Carta da transdiciplinaridade. Arrábida, Portugal: CRET.

Diário da República (1999). Despacho Conjunto 891/99, Orientações reguladoras da intervenção precoce para crianças com deficiência ou em risco de atraso grave do desenvolvimento e suas famílias. 19.10.1999. p. 15.566-15.568.

Ferreira, M. C. (2001). Organização das equipes técnicas. Em C. Louro (Org.), Acção social na deficiência (p. 78-94). Lisboa: Universidade Aberta.

Franco, V., \& Apolónio, A. (2002). Desenvolvimento, resiliência e necessidades das famílias com crianças deficientes. Revista Ciência Psicológica, 8, 40-54.

Golin, A. K., \& Ducanis, A. J. (1981). The interdisciplinary team: A handbook for the education of special children. Aspen: Rockville.

Iribarry, I. N. (2003). Aproximação sobre a transdisciplinaridade: Algumas linhas históricas, fundamentos e princípios aplicados ao trabalho de equipe. Psicologia: Reflexão e Crítica, 16(3), 483-490. 
Kupfer, M. C. (2000). Notas sobre o diagnóstico diferencial da psicose e do autismo na infância. Psicologia USP, 11(1), 85105.

Shonkoff, J., \& Meisels, S. (2000). Handbook of early childhood intervention. Cambridge University Press.

Simon, J. (1991). A integração escolar das crianças deficientes. Rio Tinto: Asa.
Unesco (1994). Declaração de Salamanca e enquadramento da acção. Conferência Mundial sobre Necessidades Educativas Especiais: Acesso e Qualidade. Lisboa: Ministério da Educação.

Recebido: $18 / 10 / 2006$ Revisado: 31/05/2007 Aceito: 09/06/2007

\section{Sobre o autor:}

Vítor Franco: Professor do Departamento de Psicologia da Universidade de Évora - Portugal.

Endereço para correspondência: vfranco@uevora.pt. 